\title{
EL PAISAJE AGRARIO Y LA PROPIEDAD DE LA TIERRA EN GUADIX DURANTE EL ANTIGUO REGIMEN (S. XVIII)*
}

\author{
Juan GAMEZ NAVARRO**
}

Como punto de partida, para situar al lector en el ámbito geográfico en que se desarrolla este estudio, hemos de indicar la situación geográfica del municipio de Guadix (Granada). Se encuentra situado en el declive norte de Sierra Nevada, en el centro-oeste de la provincia de Granada, entre los paralelos $37^{\circ}$ $06^{\circ}$ y $37^{\circ} 35^{\circ}$ de latitud norte y entre los meridianos $0^{\circ} 10^{\circ}$ y $0^{\circ} 51^{\prime}$ longitud este.

La meseta y Hoya de Guadix, de la que es Guadix capital subregional, constituye una de las regiones mejor caracterizadas de Andalucía Oriental. Su originalidad depende de manera fundamental de su situación, en el principal cruce de caminos de la Alta Andalucía, formando parte del surco penibético, que pone en contacto de Este a Oeste el Levante español con Gibraltar, y de otro lado Almería y el mediterráneo meridional con Despeñaperros y la meseta castellana. Se trata de una altiplanicie de unos mil metros de altitud media, esta es su originalidad, rodeada por un cinturón de montañas - Sierra Nevada, Sierra de Baza, Mencal, Sierra Harana- separadas por grandes pasillos, a veces de paredes escarpadas como el de Fiñana, que abre el camino hacia Almería o el de Pozo Alcón, que lo hace hacia el Guadalquivir.

\section{ANALISIS DEL TERMINO MUNICIPAL, SU EXTENSION Y LIMITES EN EL SIGLO XVIII Y COMPARACION CON EL ACTUAL}

No resulta posible conocer con exactitud ni la extensión ni los límites del término de Guadix en 1.752, pues la fuente documental básica para el estudio

* Bajo éste título el autor realizó un estudio más amplio, que fue presentado como trabajo de investigación del ciclo del Doctorado en el Dpto. de Geografía Humana de la Universidad de Granada.

** Profesor Numerario de E.M.I. 
de esta época, que el Catastro de Ensenada, integrado por el Libro de las Respuestas Generales y los de las R. Particualres, no las establece de forma clara, y además, para complicar más la cuestión, el libro de las R. Generales, que contiene las contestaciones dadas por la Comisión que elaboró el Catastro en cada pueblo, a un interrogatorio de 40 preguntas, no resuelve la cuestión al realizar una doble delimitación: el «término general» y el «término de la campaña».

El «término general» se refiere a las tierras que estaban bajo la jurisdicción del Corregimiento de Guadix, que se extendía por un amplio marco geográfico, aunque sin continuidad física; mientras que el «término de la campana» sería el correspondiente a la ciudad propiamente dicha. Así describieron los límites del término los Peritos que formaron la Comisión para la Unica Contribución, en las Respuestas Generales: «Que el término general de esta ciudad tendrá de la lebante a poniente siete leguas... y linda por lebante con los términos del Marquesado del Zenete, y villas de Gor y Esfiliana y ciudad de Baza; por el poniente con las villas de Diezma, la Peza, y Cardela; por el norte con las villas de Cazorla y Quesada y por el sur con las villas de Albuñán y Cogollos y su figura es regular...» ${ }^{1}$ (sic).

En el cuadro I incluimos la relación de cortijos que pertenecían a Guadix en 1752 y que en la actualidad están integrados en municipios distintos.

Como consecuencia de la nueva distribución superficial que se realizó en 1833, la Ciudad de Guadix perdió una parte de sus bienes de propios, que estaban Ciruelos, con una superficie de 4.651 fanegas de tierra ${ }^{2}$, que equivalen a $2.014,53$ has., de las cuales 170,35 eran de regadío; 174,25 has. de secano y el resto tierras inútiles por naturlaeza (1.670,25 has.). La superficie total de estos cortijos se eleva a 22.183 fanegas, que convertidas en has. totalizan $10.067,78^{3}$.

¿Qué superficie tenía el término de Guadix en el siglo XVIII -1752-?.

En el cuadro II se incluyen los datos disponibles aportados por el Catastro, que ponen de manifiesto la no coincidencia entre los distintos libros integrantes de éste.

Según los Estados Resúmenes, más fiables en este caso, que las Respuestas Generales $^{4}$, la superficie de Guadix ascendía a 134.961 fanegas y 1 celemín, que convertidos en has. son $58.555,0$ has.; en cmabio la superficie actual de

1. Respuesta a la $3 .^{\text {a }}$ pregunta del interrogatorio de las llamadas Respuestas Generales.

2. Según la respuesta a la $9 .^{a}$ pregunta de las R. Generales, la Fanega de tierras de regadío tiene 3.361 baras y un noveno; y la de secano el doble. Realizada la conversión resulta que la Fanega de regadío tiene $2.348,5 \mathrm{~m}^{2}$ y la de tierra de seeano $4.697 \mathrm{~m}^{2}$.

3. Falta la superficie correspondiente a los siguientes cortijos: Fonseca, Inquisidores, Cabrera, Sillar, Baños de Alicún y Lopera; debido a la pérdida de dos volúmenes de Seculares.

4. Respuesta a la décima pregunta de las R. Generales. 


\section{CUADRO I}

CORTIJOS QUE PERTENECIAN A GUADIX EN EL SIGLO XVIII Y MUNICIPIO AL QUE PERTENECEN EN LA ACTUALIDAD

\begin{tabular}{|c|c|c|}
\hline Nombre del cortijo & Municipio actual & Superficie (Has.) \\
\hline 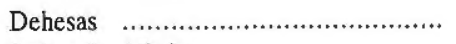 & Dehesas de Guadix .... & $1.905,56$ \\
\hline Baños de Alicún ................................ & Villanueva Torres & - \\
\hline 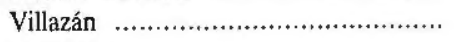 & Villanueva Tores & 180,41 \\
\hline 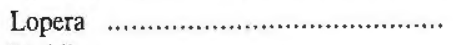 & 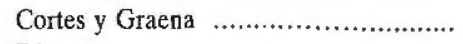 & - \\
\hline 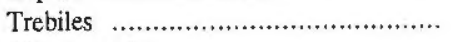 & 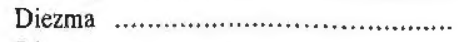 & 176,02 \\
\hline Sillar la Baja ................................ & 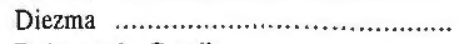 & - \\
\hline 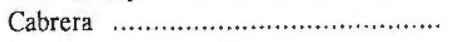 & 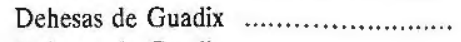 & - \\
\hline 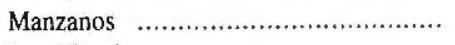 & 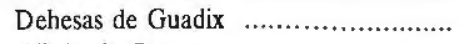 & $2.252,92$ \\
\hline 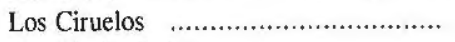 & Alicún de Ortega & 108,97 \\
\hline 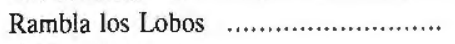 & Alamedilla & $1.042,73$ \\
\hline Fuente Caldera ................................ & Pedro Martínez . ................................ & $2.857,65$ \\
\hline 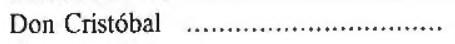 & Dehesas de Guadix .......................... & 267,72 \\
\hline 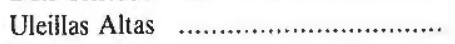 & Pedro Martínez .................................. & 220,28 \\
\hline DeI Rey & Valle del Zalabí & 20,85 \\
\hline 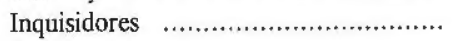 & 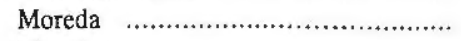 & 70,45 \\
\hline 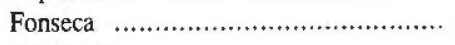 & 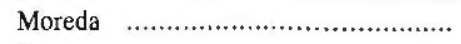 & - \\
\hline Anchurón & 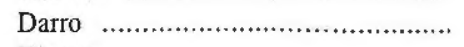 & - \\
\hline 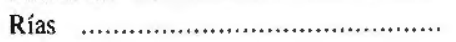 & 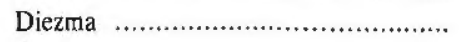 & 512,63 \\
\hline Romailique & 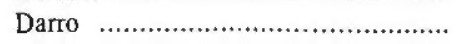 & 14,09 \\
\hline Sierra Harana & 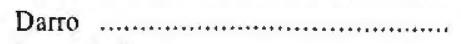 & 432,12 \\
\hline 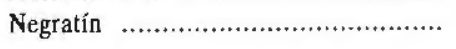 & Pozo Alcón ........................................ & 5,63 \\
\hline 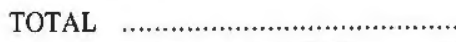 & .................. & $10.067,78$ \\
\hline
\end{tabular}

Fuente: Catastro de Ensenada y mapas topográficos.

\section{CUADRO II}

EXTENSION DEL TERMINO DE GUADIX EN 1752.

Comparación entre los datos de las Respuestas Generales y los de los Estados Resúmenes

\begin{tabular}{|c|c|c|}
\hline Tipos de tierras & L.R. Generales & Estados Resúmenes \\
\hline 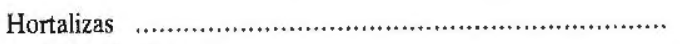 & 180 & $263-0$ \\
\hline 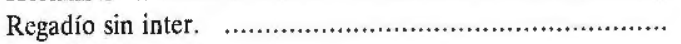 & 1.700 & $2.498-8$ \\
\hline 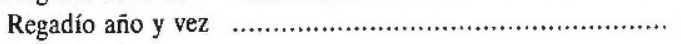 & 4.060 & $6.669-2$ \\
\hline Viñas de riego & 1.680 & $2.259-11$ \\
\hline Secanos & 2.000 & $9.906-1$ \\
\hline Eras para trillar & 45 & $52-6$ \\
\hline 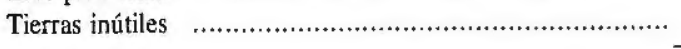 & 50.000 & $113.311-4$ \\
\hline TOTAL & 59.665 & $134.961-1$ \\
\hline
\end{tabular}

Fuente: Catastro de Ensenada (Datos en faengas-cel). 
Guadix es de 32.493 has., diferencias que se explican porque los término «general» de la ciudad en el siglo XVIII y el actual corresponden a realidades geográficas muy distintas.

Con los datos disponibles no nos es posible reconstruir un mapa con la delimitación municipal precisa. Sin embargo, para dar una idea aproximada de la extensión que tenía Guadix, hemos incluido el mapa $n .{ }^{\circ} 2$, en el que sobre la base de un mapa actual, escala 1:200.000, de los municipios de la comarca, hemos reflejado la situación de los cortijos pertenecientes a Guadix en 1752; y en el mapa III hemos realizado una comparación entre los términos «general», de la «campana» y el actual término, dándose una casi coincidencia entre el de la «campana» y el actual, establecido en 1833 .

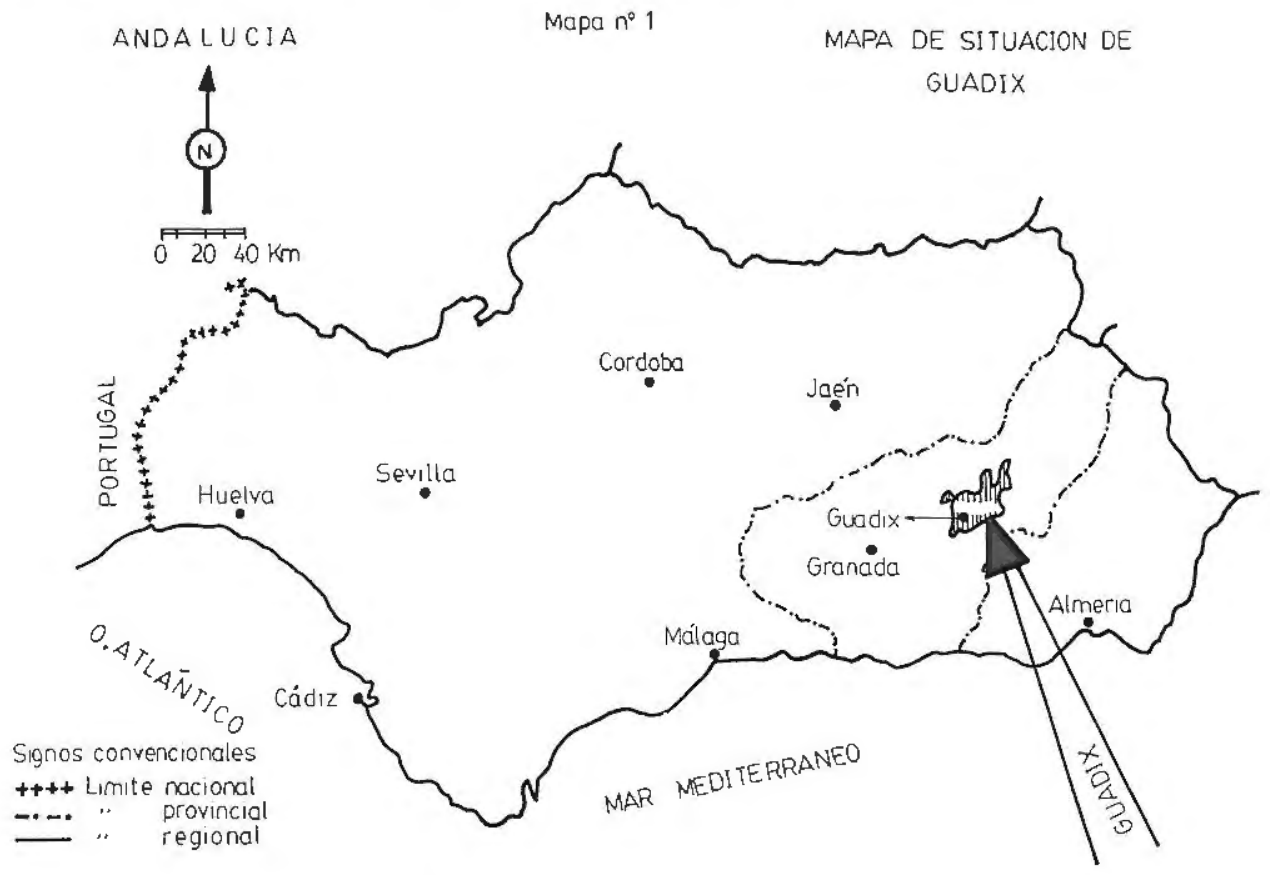

\section{CULTIVOS Y PRODUCCION}

Tras haber realizado el necesario análisis del término municipal, en la medida que las fuentes disponibles, lo permiten, pasamos a estudiar las características del paisaje agrario accitano en el $\mathrm{s}$. XVIII.

En adelante la fuente documental utilizada son las Respuestas Particulares, (libros que contienen los datos de las tierras declaradas por cada propietario, previa clasificación de clases realizada por la Comisión), porque es la fuente 


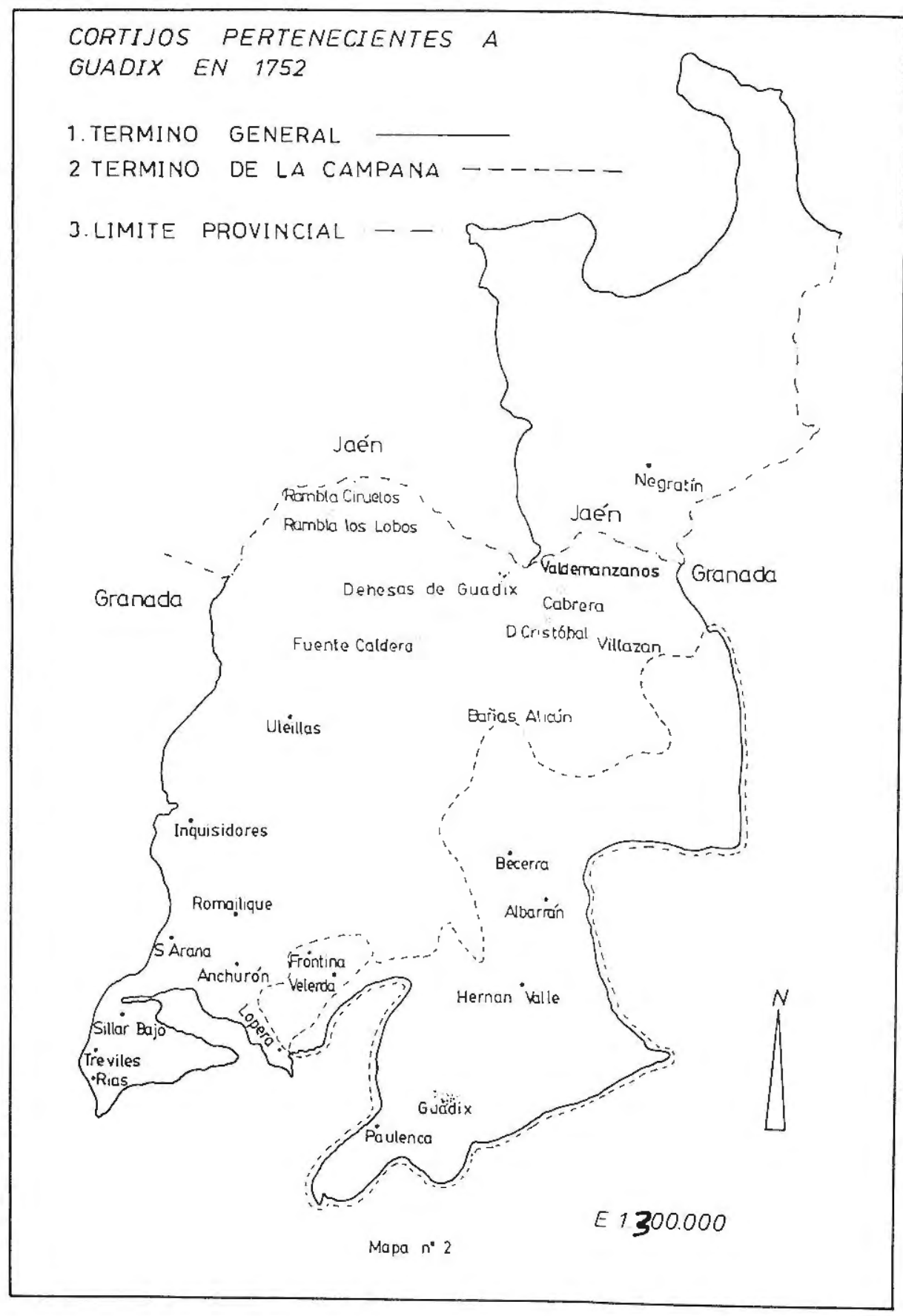




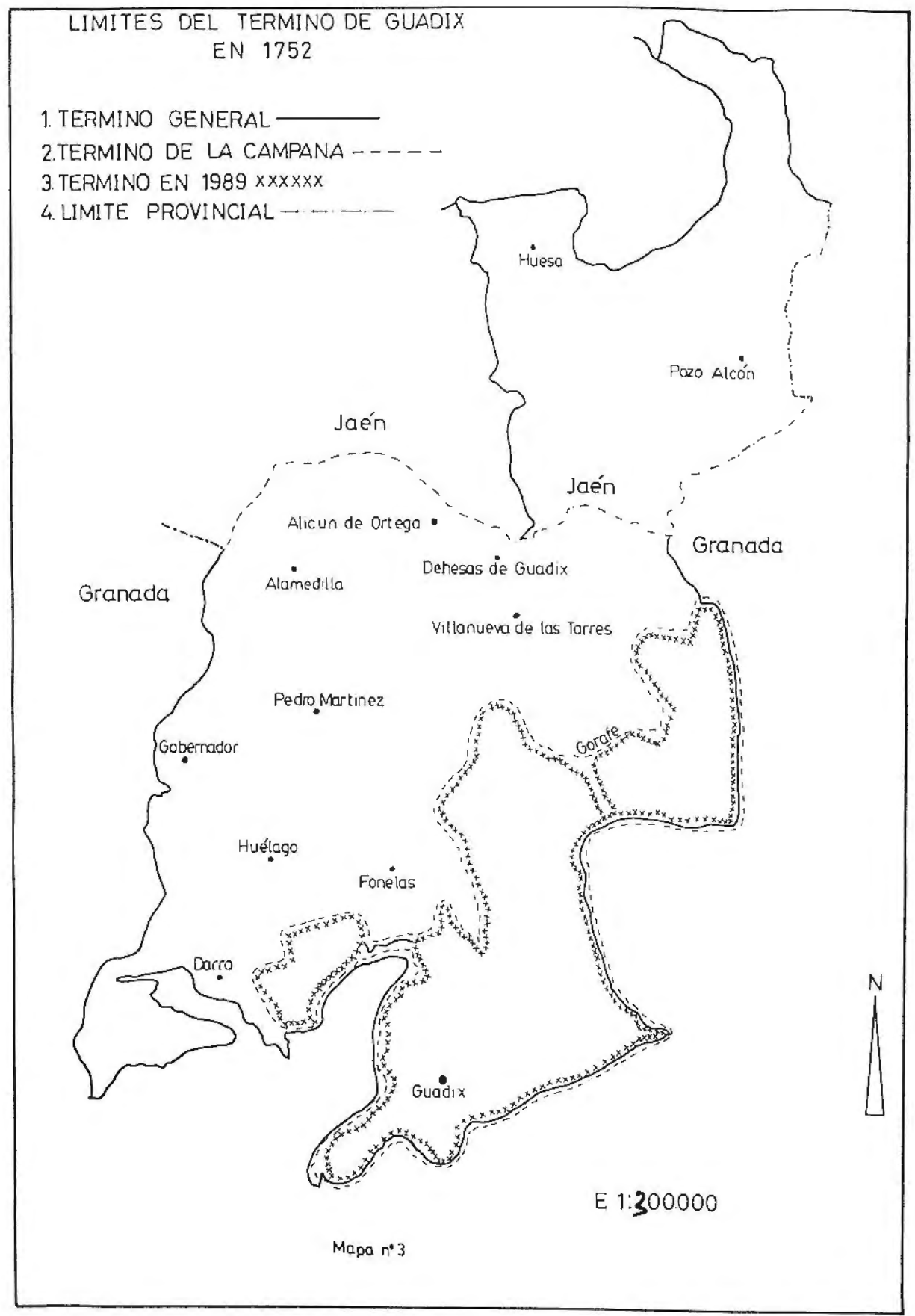

[6] 
más fidedigna, pese a estar incompletos los Libros de Seculares, que recordamos debíanser cinco, de los cuales sólo se conservan tres -el $1 .^{\circ}, 3 .^{\circ}$ y $5 .^{\circ}-$, en el Archivo de la Real Chancillería, porque es la fuente que permite un análisis pormenorizado de las parcelas, sus calidades, y de las propiedades; no así de los cultivos, que debemos deducir por la información que proporcionan, tanto las R. Generales como la Nota de Valor: documento básico para el cálculo de la riqueza, ya que en el se tipifican las clases de tierras, sus calidades agronómicas, sus cultivos, y su clase fiscal, indicando su producción en reales y maravedíes.

Tras un recuento minucioso de las declaraciones de los propietarios incluidas en las R. Particulares, hemos obtenido los siguientes datos, que reflejamos en el cuadro n. ${ }^{\circ}$ III, con indicación de los tipos de tierras y sus calidades (ver gráfico I).

\section{CUADRO III}

TIPOS DE TIERRAS Y SUS CALIDADES. GUADIX, 1752

\begin{tabular}{|c|c|c|c|c|}
\hline Tipos de tierras & Calidad & Superf. (fgas.) & Superf. (has.) & $\%$ \\
\hline 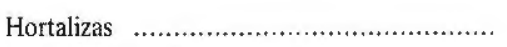 & $1 .^{\mathrm{a}}$ & $189-7$ & 44,52 & 2,2 \\
\hline \multirow[t]{3}{*}{ Regadío sin inter. } & $1 .^{a}$ & $1.468-6$ & 344,87 & 17,3 \\
\hline & $2 .^{a}$ & $568-7$ & 133,51 & 6,7 \\
\hline & $3 .^{\mathrm{a}}$ & $66-7$ & 15,64 & 0,8 \\
\hline \multirow[t]{3}{*}{ 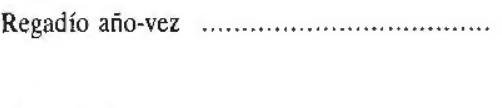 } & $1 .^{a}$ & $1.478-6$ & 347,22 & 17,4 \\
\hline & $2 .^{a}$ & $2.061-8$ & 484,19 & 24,3 \\
\hline & $3 .^{a}$ & $1.524-5$ & 358,02 & 17,9 \\
\hline \multirow[t]{3}{*}{ 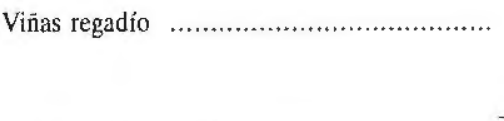 } & $1 .^{a}$ & $694-4$ & 163,07 & 8,2 \\
\hline & $2 .^{\mathrm{a}}$ & $246-1$ & 55,77 & 2,8 \\
\hline & $3 .^{\mathrm{a}}$ & $194-4$ & 45,65 & 2,3 \\
\hline TOTAL REGADIO $\left({ }^{*}\right)$ & - & $8.492-7$ & $1.992-46$ & 7,6 \\
\hline SECANOS & $3 .^{a}$ & $5.346-0$ & $2.511,01$ & 9,6 \\
\hline TIERRA INUTIL & - & $46.025-5$ & $21.618,14$ & 82,8 \\
\hline
\end{tabular}

( $\left.{ }^{*}\right)$ Los porcentajes del regadio están calculados sobre el total de éste.

Fuente: R. Particulares Catastro Ensenada.

La relación existente entre las tierras cultivadas y las no cultivadas o infructíferas, según el Catastro, es claramente favorable a éstas últimas, ya que suponen el $82,7 \%$ del total; en cambio, las cultivadas representan el $17,3 \%$ restante.

Las tierras que más interesan desde el punto de vista agronómico son las cultivadas, por ser las más productivas, aunque no debemos olvidar que la valoración que se hizo en el Catastro es exclusivamente fiscal, por lo que a las tierras infructíferas se refiere, pero hay que tener en cuenta que desde el punto de vista ganadero tienen algún valor por sus pastos y también como abastecedoras de combustible para los hogares de los más desfavorecidos. 
Dentro del grupo de las tierras cultivads merecen especial atención las de regadío, que totalizan 8.492 fanegas y 7 celemines, el 44,3\%.

Sin embargo, existen diferencias cuantitativas y cualitativas entre ellas de forma que las que producen todos los años «sin intermisión», ascienden a 2.103 fanegas y 8 celemines (el 24,7 \%), mientras que las de «año y vez» suponen 5.064 fanegas y 7 celemines (el 59,6\%); es decir, algo más de la mitad del regadío produce una cosecha cada dos años. El resto son viñas de regadío, 1.139 fanegas (el 13,3 \%), y unas pocas tierras de hortalizas, 189 fanegas $(2,3$ $\%)$, únicas tierras que producen dos cosechas al año.

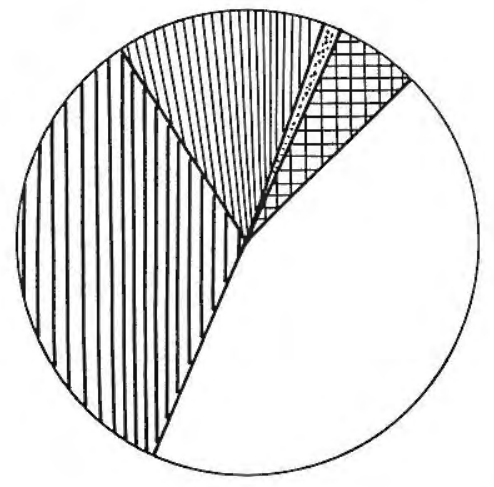

HORTALIZAS

IIIIIII REGADIO SIN INTERMISION

IIIII) REgADIO DE AÑO Y VEZ

UIÑAS

$\square$ SECANOS

Fuente: C. Ensenada

GRAFICO $\cap^{\circ} 1$

Las tierras de secano totalizan 5.346 fanegas, que suponen 2.511 has., el $55,7 \%$ de las tierras cultivadas, siendo su productividad muy inferior a las de regadío, ya que producen una cosecha cada tres años; es decir, son de rotación trienal, lo que determina su escaso valor fiscal, establecido en 16 reales por fanega de tierra. Se cultivan exclusivamente de centeno, cereal poco exigente en suelos y cultivable con poca humedad en el suelo.

El problema principal radica en saber si las superficies declaradas eran exactas o si por el contrario hubo ocultación fiscal. Puesto que se trata de un documento de carácter fiscal nunca puede excluirse tal posibilidad, aunque creemos que la ocultación no se dio tanto en la declaraciones de superficies (salvo, tal vez, en los cortijos, propiedad de los grandes propietarios, de los que se hizo una valoración global y aproximativa, lo que deducimos por lo redondeadas que aparecen las superficies declaradas), porque eran comprobadas «in situ» al tratarse de un Catastro; como en las calidades, que se infravaloraron y en la rotación de cultivos, normalmente exagerada para disminuir el valor 
fiscal de las tierras; es decir se declaran intencionadamente rendimientos inferiores a los reales, como ha puesto de manifiesto C. CAMARERO BULLON ${ }^{5}$ en su estudio sobre la producción agraria en el siglo XVIII.

La comparación entre las dos fuentes que componen el Catastro podría arrojar cierta luz sobre este particular, aunque las R. Generales, como han puesto de manifiesto otros investigadores ${ }^{6}$, pueden no ser suficientemente precisas, y además en el caso de Guadix no nos es posible comparar al faltar dos volúmenes de seculares. Esta es, sin duda, la limitación fundamental de nuestro estudio, lo que determina que aunque nos referimos a Guadix, como término municipal, la realidad es que la superficie total manejada es inferior a la real. Los datos disponibles serían suficientes para un análisis de la propiedad porque son representativos, pero no para el estudio global del paisaje agrario.

Conocer la distribución real de cultivos es prácticamente imposible, ya que no se menciona nada al respecto en las declaraciones recogidas en las R. Particulares. Por ello los hemos deducido, en base a los datos aportados por las R. Generales y en la Nota de Valor, aunque existen ciertas discrepancias entre ambas, ya que la Nota de Valor simplifica al máximo la rotación de cultivos, mientras que en las R. Generales, en cambio, la rotación es más compleja.

Los cultivos predominantes en las tierras de regadío «sin intermisión» eran el trigo, ya que más de la mitad de ellas se sembraban de este cereal $(52,4 \%)$. La cebada sólo ocnpaba el $10 \%$. Es de resaltar la importancia de los cultivos industriales: el lino $(4,7 \%)$, y el cáñamo $(19,4 \%)$, relacionados con la producción artesanal de sogas y aperos de labranza y carga utilizados por los arrieros, muy abundantes en aquélla época en Guadix (ver cuadro IV y gráfico II). Además de éstos, otros cultivos menos representativos, pero importantes para la economía rural, basada en una agricultura tradicional de autoconsumo, como habas $(7,9 \%)$, habichuelas y los dedicados a la alimentación del ganado doméstico de consumo familiar, como son el mijo, maíz, nabos (5,9\%), completan la distribución de cultivos en las tierras de regadío, de la que producen todos los años. En cambio, en la Nota de Valor, los cultivos se reducen a cuatro: trigo, habas, lino y cáñamo.

La Nota de Valor clasifica estas tierras en tres calidades agronómicas: $1 .^{\mathrm{a}}$, $2 .^{\mathrm{a}}$ y $3 .^{\mathrm{a}}$, que se corresponden con las clases fiscales $2 .^{\mathrm{a}}, 3 .^{\mathrm{a}}$ y $4 .^{\mathrm{a}}$, valoradas en 228 rs. y 26 mrs.; 190 rs. y 26 mrs.; y 188 rs. y 18 mrs. respectivamente. Los valores calculados por nosotros coinciden prácticamente con los reflejados en la Nota de Valor, produciéndose tan sólo leves variaciones.

\footnotetext{
5. CAMARERO BULLON, C. «La producción agraria en el siglo XVIII». Estudios Geográficos, n. ${ }^{\circ} 174$, págs. 102-105.

6. FERRER RODRIGUEZ, A. «El paisaje agrario de Alhama de Granada en el siglo XVIII», Caja General Ahorros de Granada, 1975, pág. 106.
} 


\section{CUADRO IV}

TIERRAS CULTIVADAS ANUALMENTE EN GUADIX, SU PRODUCCION, Y SU VALOR EN REALES DE VELLON

\begin{tabular}{|c|c|c|c|c|}
\hline Tipo de tierra y cultivo & $\begin{array}{l}\text { Fgas. sembradas } \\
\text { Total }\end{array}$ & $\begin{array}{c}\text { Fgas, sembradas } \\
\%\end{array}$ & $\begin{array}{l}\text { Producción } \\
\text { (fanegas) }\end{array}$ & $\begin{array}{l}\text { Valor } \\
\text { Is. }\end{array}$ \\
\hline \multicolumn{5}{|l|}{ R.S. Intermisión } \\
\hline 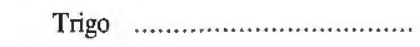 & 1.102 & 52,4 & 10.402 & 187.249 \\
\hline Cebada & 210 & 10,1 & 2.952 & 26.570 \\
\hline 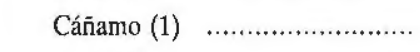 & 411 & 19,5 & 1.026 & 128.448 \\
\hline 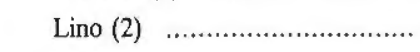 & 103 & 4,8 & 222 & 21.437 \\
\hline 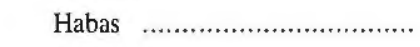 & 166 & 7,9 & 1.528 & 27.517 \\
\hline Habichuelas ........................... & 28 & 1,3 & 98 & 2.936 \\
\hline Mijo & 27 & 1,3 & 250 & 2.500 \\
\hline 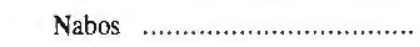 & 28 & 1,3 & $6.278 \mathrm{a}$ & 3.139 \\
\hline 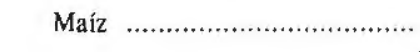 & 28 & 1,3 & 250 & 3.002 \\
\hline TOTAL & 2.103 & 24,8 & - & 402.798 \\
\hline \multicolumn{5}{|l|}{ R. año y vez } \\
\hline 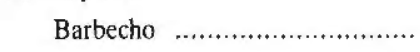 & 2.532 & 50,0 & 0 & 0 \\
\hline 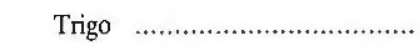 & 1.323 & 26,1 & 9.642 & 173.556 \\
\hline Cebada & 839 & 16,6 & 7.717 & 69.453 \\
\hline 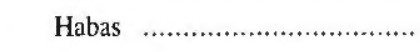 & 61 & 1,2 & 492 & 8.856 \\
\hline Garbanzos $\quad \ldots \ldots \ldots \ldots \ldots \ldots \ldots \ldots \ldots \ldots \ldots \ldots \ldots \ldots$ & 61 & 1,2 & 185 & 5.535 \\
\hline Centeno & 247 & 4,9 & 988 & 13.832 \\
\hline 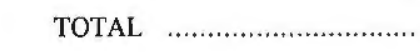 & 5.063 & 59,6 & 19.024 & 271.234 \\
\hline 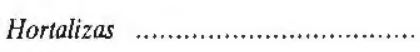 & 189 & 2,2 & - & 62.568 \\
\hline Viñas & 1.134 & 13,4 & $59.352 \mathrm{a}$. & 89.028 \\
\hline Arbolado & - & - & - & 115.131 \\
\hline 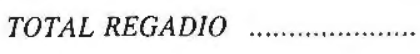 & 8.489 & 100,0 & - & 940.760 \\
\hline 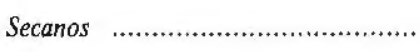 & 5.346 & - & 21.384 & 99.793 \\
\hline 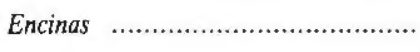 & - & - & - & 10.005 \\
\hline SUPERFICIE TOTAL ............... & 13.835 & 100,0 & - & 1.050 .557 \\
\hline
\end{tabular}

(1)-(2) Se incluye en el valor total la producción de semilla: linaza y cañamón.

Fuente: R. Generales y Nota de Valor. Elaboración propia. 
En las tierras de regadío de «año y vez», es decir, aquellas que se siembra un año con descanso de otro, predominan los cereales, y entre ellos, el trigo, que ocupaba el $52,1 \%$ de la superficie cultivada, que gana en extensión a la cebada, que ocupa el $33,1 \%$, y al centeno que se extiende por el $9,8 \%$ de estas tierras. Con respecto a las tierras de regadío «sin intermisión» la cebada ha incrementado sustancialmente su superficie y además aparece el centeno en las de tercera calidad. Las habas y los garbanzos completan el cuadro de cultivos. Estamos ante unas tierras que bien podíamos llamar de «pan llevar», aunque sin olvidar la presencia de cultivos industriales en las tierras de regadío sin descanso, y de leguminosas de consumo humano y animal en ambas. Estas tierras las clasifica la Nota de Valor en tres calidades agronómicas: $1 .^{\mathrm{a}}, 2$. $^{\mathrm{a}}$ y $3 .^{a}$, que se corresponde con las clases fiscales $8 .^{a}, 9 .^{a}$ y $12 .^{a}$, con un valor de 65 rs. y 8 mrs.; 58 rs. y medio; y 33 rs. respectivamente, que coinciden prácticamente con los calculados por nosotros.

\section{CULTIVOS EN LAS TIERRAS DE SEMBRADURA. \\ GUADIX, 1.752 .}

\section{1.-REGADIO SIN INTERMISION.}

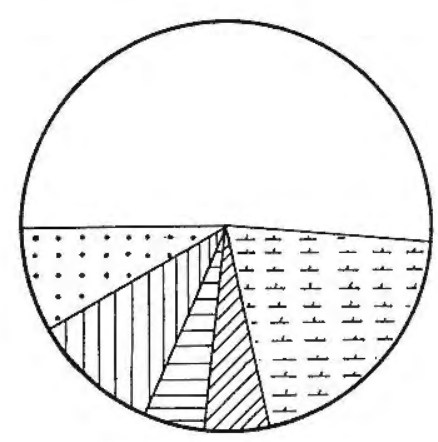

GRAFICO $\cap^{\circ} 2$
2.- REGADIO DE AÑO Y VEZ.

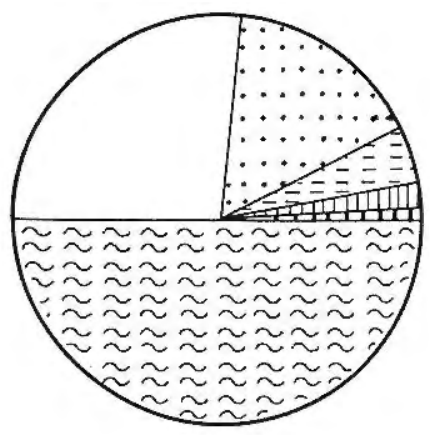

DIIIA VARIOS

ПDП gaRBAnzOS

EZZ CENTENO

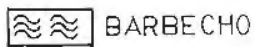

Fuente C.Ensenada 
Completan la distribución de cultivos de las tierras de regadío las sembradas de hortalizas y las plantadas de viñas, clasificadas éstas últimas en tres calidades agronómicas: $1 .^{a}, 2 .^{a}$ y $3 .^{a}$, a las que se asigna un valor fiscal de 96,72 y 24 reales respectivamente.

No debemos olvidar que tanto en las tierras de regadío sin intermisión como en las de viñas, había plantados árboles frutales dispersos y en las orillas de las parcelas, predominando los ciruelos (21.292 unidades), los guindos (10.236), los perales (3.059), los manzanos (2.954), y los castaños (1.552). Había también membrilleros, servales, cerezos, duraznos y nísperos. Además están presentes el olivo (1.734 unidades) y el almendro (474). Destaca la gran importancia del moral para la cría del gusano de seda con 6.525 ejemplares, que producían la renta más elevadas de todas las especies arbóreas, 24.469 rs.

En las tierras de secano, que son las de menor valor fiscal, valoradas en 16 reales por fanega, valor inferior en dos reales al calculado por nosotros, y todas son de mala calidad. Se cultivan al tercio; es decir, un año producen y descansan lso dos siguientes. El único cultivo es el centeno, cereal adaptado a la mala calidad de los suelos y a la escasez de agua. En estas tierras y en las inútiles por naturaleza había tres especies de árboles: las encinas, los pinos y los árboles de ribera a los que no se calcula valor fiscal, salvo a las encinas por su producción de bellota.

En las tierras inútiles, sin valor fiscal según el Catastro, pastaban los escasos ganados, predominando las especies menores, cabrío con 5.944 cabezas y lanar con 5.863 cabezas. Tuvo gran importancia el ganado de cerda $(2.553$ cabezas), fundamental para la despensa familiar anual, y sobre todo el vacuno utilizado para la labor (1.046 cabezas). la ganadería menor estaba concentrada en pocas manos, ya que siete propietarios con más de 400 cabezas acaparan el $37 \%$ del total; y los propietarios de más de 200,22 en total, acaparan el $68 \%$ del ganado.

La simbiosis entre agricultura y ganadería, y no oposición frontal como se daba en otros lugares del país, la podemos deducir a través de dos manifestaciones: por una parte, la profesión que declaran los propietarios de ganado, casi todos aparecen como labradores; y por otra, fijándonos en el ganado de tiro, de labor que declaran poseer, lo que nos hace pensar que son verdaderos labradores. En todo caso la importancia de la ganadería con respecto a la agricultura era muy pequeña, ya que participaba en la renta agrícola con un porcentaje mínimo; además el medio natural no favorecía esta práctica pues las amplias extensiones de erial y espartial son poco aptas para el desarrollo de la ganadería, de hecho el rebaño más numeroso de 2.500 cabezas estaba en el término municipal de Huéscar.

¿Cómo se cultivaban estas tierras? ¿Cómo estaban repartidas? Responder a la primera pregunta exige hablar de los sistemas de rotación y de los regíme- 
nes de tenencia de la tierra. Respecto a los sistemas de rotación hay que decir que el regadío de rotación anual se extiende por el 17,8 \% de las tierras; la rotación bienal se practicaba en el $26,4 \%$ de la superficie; mientras que la rotación trienal, exclusiva del secano, se daban en el $55,8 \%$ de la superficie cultivada.

Esta distribución nos lleva a pensar en la no existencia de una división del terrazgo en hojas, fruto de explotaciones basadas en usos y costumbres comunitarias; sino más bien nos inclinamos por pensar que las formas de explotación estaban organizadas en torno a los ríos aprovechando al máximo el agua de riego, concentrándose las tierras «sin intermisión» en las proximidades de la ciudad, siguiendo el curso del río Guadix, produciéndose una parcelación máxima en las cercanías de la ciudad, que se va incrementando a medida que nos alejamos de la ciudad, pasando la rotación a ser bienal. Algo similar ocurre en los cortijos o núcleos rurales de población, en cuyas proximidades se situaba el escaso regadío, mientras que los secanos son las tierras más alejadas.

Respecto a las técnicas agrícolas utilizadas y a los regímenes de tenencia, el Catastro nada o casi nada dice, privándonos del conocimiento de aspectos fundamentales. La única referencia indirecta, que sobre los regímenes de tenencia viene recogida en el volumen $\mathrm{V}$ de seculares; según el resumen incluido en este volumen existían en Guadix entre los vecinos seculares 34 colonos de haciendas de eclesiásticos, a los que se regulaba una utilidad por el arriendo de 17.881 reales. Se especifica que había 576 jornaleros, que ganan a razón de 3 reales diarios durante unos ocho meses al año. También había dos colonos entre los eclesiásticos (eran presbíteros), y entre las profesiones liberales existían personas que llevaban tierras en régimen de colonato.

Estos datos, aunque parciales, pues nada indican de la superficie cultivada bajo este sistema de explotación, junto con otros recogidos de los libros de Protocolos Notariales de Guadix, y además por la existencia de un numeroso colectivo de personas, 117 vecinos incluidos en los cortijos, que aparecen en el Catastro como labradores, y sin embargo no poseen tierras en propiedad o poseen una escasa superficie, nos lleva a deducir que el arrendamiento estaba bastante generalizado, especialmente entre los propietarios absentistas, siendo absolutamente predominante en los cortijos, que son propiedad de la nobleza, de propietarios forasteros con residencia en Granada y de eclesiásticos?

Los contratos de arrendamiento tenían una duración corta, que oscila entre 3 y 6 años, si bien hemos encontrado alguno de 9 años de duración. La renta se establecía siempre en especie (trigo, cebada y paja) porque la subida de

7. ARTOLA, Miguel. «El latifundio: propiedad y explotación. Siglos XVIII-XX», ed. Ministerio de Agricultura, Madrid, 1976, pág. 49-51. 
los precios aconsejaba esta práctica. Además se estipulaban el pago de gallinas, que recuerdan los derechos de jurisdicción. Todos los contratos incluyen además la posibilidad de declarar esterilidad, por plagas o por granizo, y el compromiso de labrar la tierra a uso de buenos labradores ${ }^{8}$.

\section{ESTRUCTURA DE LA PROPIEDAD}

El estudio de la propiedad de la tierra tropieza con un problema fundamental: el establecimiento de grupos o categorías estadístico, bien en base a la superficie o bien en base a la renta producida, en los que fundamentar dicho análisis.

Los intervalos utilizados son todos discutibles, pero a la postre necesarios y útiles, sobre todo si se tiende a establecer categorías generales que permitan utilizar todos los trabajos o monografías de un determinado período histórico, a fin de reconstruir las características del paisaje agrario andaluz del siglo XVIII. En opinión de MATA OLMO ${ }^{9}$ estos indicadores aunque sumamente útiles e ineludibles en el empleo de fuente convencionales no son más que indicadores económicos o espaciales del contenido esencial de la gran propiedad tradicional: el trabajo asalariado masivo, la baja composición orgánica del capital y la modesta productividad... Es difícil señalar con precisión umbrales superficiales, de producto o de ingresos por encima de los cuales este tipo de relaciones y organización agrarias se hacían dominantes.

Pese a todo, los umbrales hay que utilizarlos y aunque no vamos a entrar en las diferentes clasificaciones que se han utilizado, vamos a optar por la que a nuestro juicio es más adecuada para la zona de estudio... En este sentido consideramos pequeña propiedad o minifundio a todas aquéllas que tengan menos de 10 Has.; por contra la gran propiedad estaría integrada por aquéllas propiedades con más de 100 Has. ${ }^{10}$.

Pero antes de analizar los diferentes grupos superficiales hemos creído conveniente, puesto que se trata de una sociedad distinta, con unas categorías sociales muy específicas, estudiar los propietarios según su extracción social. La primera diferencia que llama la atención es la separación entre seculares y eclesiásticos, cuyas propiedades quedan reflejadas en el cuadro $\mathrm{V}$.

8. Archivo de Protocolos Notariales de Guadix. Sin clasificar. Legajos años 1753-1765. Notario D. Francisco Espinosa, hojas 18-21. Y otros correspondientes a los años 1716 y 1748.

9. MATA OLMO, R. «Pequeña y gran propiedad agraria en la depresión del Guadalquivir», ed. Ministerio de Agricultura, Pesca y Alimentación. Madrid, 1987, págs. 17-26.

10. BOSQUE MAUREL, J. «Latifundio y minifundio en Andalucía oriental». Estudios Geográficos, Madrid, C.S.I.C., 1974, págs. 5-48; y CANO GARCIA, G. «La comarca de Baza», Valencia, 1974, Dpto. de Geografía, pág. 256. 
CUADRO $\mathrm{V}$

PROPIEDADES ECLESIASTICAS Y SECULARES (HAS.)

\begin{tabular}{|c|c|c|c|c|c|}
\hline Propietarios & Regadío & Secano & Inútil & Total & $\%$ \\
\hline 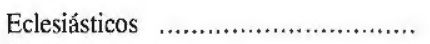 & $1.063,99$ & $1.077,0$ & $3.362,2$ & $5.503,16$ & 21,0 \\
\hline 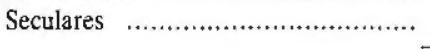 & 934,01 & $1.434,9$ & $18.249,3$ & $20.618,04$ & 79,0 \\
\hline TOTAL & $1.998,0$ & $2.511,9$ & $21.611,5$ & $26.121,20$ & 100,0 \\
\hline
\end{tabular}

Fuente: R. Particulares Catastro Ensenada.

Se aprecia un dominio selectivo de las tierras mejores por parte de los eclesiásticos, ya que controlaban el 53,2 \% del regadío. Las razones que pueden explicar esta acumulación de tierras de regadío en manos de los eclesiásticos pueden deberse al mayor control que ejercían sobre la población, al ser sede episcopal, a la posibilidad de adquirir mejores tierras por disponer de rentas más elevadas y a las frecuentes donaciones que hacían aumentar continuamente su patrimonio a costa de las tierras en manos libres. Por contra, los secanos están dominados por los seculares, que controlan el $57,3 \%$, porcentaje que se incrementa hasta el $84,5 \%$ en las tierras inútiles por naturaleza, integradas por atochares, tomillares, monte bajo...

Las propiedades eclesiásticas se encuentran distribuidas de forma muy desigual y repartidas entre propietarios de muy diversos tipos: sacristanes, obras pías, dignidades de la Catedral, Ordenes Religiosas... En todo caso se dio una clara concentración en algunas instituciones y órdenes religiosas. Los diez propietarios con más de 10.000 reales de renta, que aparecen recogidos en el cuadro VI, acaparan el $60 \%$ del regadío, más del $68 \%$ del secano y el $60 \%$ de las rentas eclesiásticas.

\section{CUADRO VI}

PROPIETARIOS ECLESIASTICOS DE MAS DE 10.000 REALES. (HAS.)

\begin{tabular}{|c|c|c|c|c|c|}
\hline Propietarios & Regadío & Secano & Inútil & Total & $\%$ \\
\hline Cía. de Jesús .............................. & 103,74 & 140,96 & $2.397,80$ & $2.642,5$ & 48,1 \\
\hline 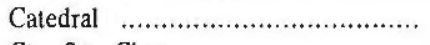 & 132,74 & 16,06 & 27,54 & 176,3 & 3,2 \\
\hline Cto. Sta. Clara …............................ & 110,78 & 326,68 & 397,29 & 834,7 & 15,2 \\
\hline Cto. Concepción .......................... & 82,35 & 70,99 & 74,25 & 227,6 & 4,1 \\
\hline Cto. Sto. Domingo ........................ & 28,80 & 120,43 & 4,60 & 153,8 & 2,8 \\
\hline Cto. Sta. Clara-Baza ..................... & 40,47 & 31,60 & 283,02 & 355,1 & 6,4 \\
\hline Antonio Ibáñez .............................. & 63,46 & 12,18 & 20,08 & 95,7 & 1,7 \\
\hline Pascual Torregr. ......................... & 32,84 & 3,05 & 1,81 & 37,7 & 0,7 \\
\hline Hospital Real ................................ & 17,96 & 17,45 & 0,15 & 35,6 & 0,6 \\
\hline Francisco Martínez . ......................... & 20,50 & 0,00 & 0,11 & 20,6 & 0,4 \\
\hline TOTAL & 633,64 & 739,40 & $3.206,69$ & $4.579,7$ & 73,2 \\
\hline
\end{tabular}

Fuente: R. Particulares Catastro Ensenada (Los porcentajes se han calculado sobre el total de tierras eclesiásticas). 
La Catedral de Guadix es el mayor propietario eclesiástico, concentrando en sus manos el $12,5 \%$ de las mejores tierras de regadío y el $16,5 \%$ de la renta total de eclesiásticos, desequilibrio en favor de la renta que viene explicado por la gran calidad de las tierras que tiene en propiedad. A nivel superficial es la Compañía de Jesús la que acapara mayor superficie, el $48 \%$, si bien una parte considerable son tierras inútiles.

Los propietarios Seculares, suponen el $61,4 \%$ del total y controlan el $79 \%$ de las tierras. Es éste un colectivo muy heterogéneo, pues lo único que les une es no pertenecer al orden eclesiástico; sin embargo, las grandes diferencias sociales y económicas existentes en este grupo, que lo es sólo a efectos estadísticos, nos lleva a realizar un análisis separativo siguiendo las pautas habituales de clasificación para la sociedad del s. XVIII, a saber: nobleza, estado llano y bienes comunales, y cuyos datos incluimos en el cuadro VII.

CUADRO VII

PROPIEDADES SECULARES SEGUN LA EXTRACCION SOCIAL DE SUS PROPIETARIOS

\begin{tabular}{|c|c|c|c|c|c|c|}
\hline \multirow{2}{*}{ Grupo social } & \multicolumn{2}{|c|}{ Propietarios } & \multicolumn{2}{|c|}{ Productos reales } & \multicolumn{2}{|c|}{ Superficie (Has.) } \\
\hline & Total & $\%$ & Total & $\%$ & Total & $\%$ \\
\hline Nobleza y O.N. . .......................... & 19 & 9,0 & 179.723 & 37,8 & $3.208,9$ & 15,6 \\
\hline 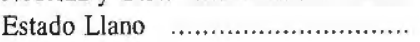 & 189 & 90,0 & 241.190 & 50,7 & $3.704,5$ & 17,9 \\
\hline B. Comunales $\quad$.............................. & 2 & 1,0 & 55.042 & 11,5 & $13.702,2$ & 66,5 \\
\hline TOTAL & 210 & 100,0 & 475.955 & 100 & $20.615,6$ & 100,0 \\
\hline
\end{tabular}

Fuente: R. Particulares Catastro Ensenada. Guadix.

Destaca la gran importancia del E. Llano, que como colectivo supone el 90 $\%$, pero sólo controla el $17,9 \%$ de la superficie de los seculares; si bien su riqueza asciende al $50,7 \%$ del total, produciéndose un fuerte desequilibrio, debido a que suelen ser propietarios de tierras de regadío y cultivadas con mucha atención e interés, produciéndo una media de 65 reales por Ha.; mientras que las de la nobleza producen 56 rs./ha. y los bienes comunales 4 rs./ha.

Las desigualdades son evidentes, sin embargo, no llegan a reproducir fielmente la estructura social estamental del Antiguo Régimen, ya que si bien la nobleza y el clero controlan una parte sustancial de la tierra, ya no se da un predominio absoluto de los dos estamentos privilegiados. Además las diferencias abismales que se producen en este colectivo, determinan que una parte estos integrantes carezcan de poder económico, entendiendo éste como el dominio sobre la tierra. De alguna forma esta situación nos lleva a pensar en la existencia de una cierta descomposición interna en la sociedad estamental accitana, en la que se aprecian cambios que denotan que miembros del E. Llano, 
especialmente profesiones liberales, mercaderes y algunos forasteros, de alguna forma empiezan a ser un elemento decisivo en el dominio de la propiedad de la tierra, fuente de riqueza consustancial con el Antiguo Régimen.

Entre los propietarios nobles se dan, por una parte, unas diferencias significativas entre sus integrantes; y por otra, una gran concentración de la propiedad, de hecho siete de ellos, todos con rentas superiores a 10.000 reales, acaparan la mayor parte de las tierras del grupo, el $80,3 \%$ y el $85 \%$ de las rentas.

Entre estos doce propietarios controlan la mayor parte de las tierras de seculares, aunque el porcentaje de la renta es sensiblemente inferior por la gran cantidad de tierras improductivas.

CUADRO VIII

PROPIETARIOS SECULARES CON MAS DE 10.000 REALES DE RENTA

\begin{tabular}{|c|c|c|c|c|}
\hline \multirow{2}{*}{ Nombre propietario } & \multicolumn{2}{|c|}{ Superficie (Has.) } & \multicolumn{2}{|c|}{ Renta (Reales) } \\
\hline & Total & $\%$ & Total & $\%$ \\
\hline 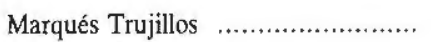 & 892,1 & 4,30 & 36.722 & 7,71 \\
\hline Marqués de Cortes ......................... & $1.072,0$ & 5,17 & 30.132 & 6,33 \\
\hline Marqués Villalegre ....................... & 31,0 & 0,14 & 23.635 & 4,96 \\
\hline Marqués Villanueva ........................ & 456,4 & 2,20 & 17.012 & 3,57 \\
\hline M. Torres, Caballero ........................ & 82,4 & 0,40 & 17.029 & 3,57 \\
\hline P. Alcántara, Caballero ................. & 18,9 & 0,09 & 15.215 & 3,19 \\
\hline J. Carrasco, Rexidor ..................... & 23,0 & 0,11 & 14.432 & 3,03 \\
\hline Ciudad de Guadix , ........................... & $13.672,0$ & 66,48 & 54.302 & 11,40 \\
\hline Nicolasa Merino ............................ & $2,963,3$ & 14,30 & 60,361 & 12,68 \\
\hline María de Vera .............................. & 92,4 & 0,44 & 12.689 & 2,66 \\
\hline Antonia Moreda ........................... & 51,5 & 0,25 & 14.879 & 3,12 \\
\hline Juan Pérez Herrasti ....................... & 34,2 & 0,16 & 16.990 & 3,56 \\
\hline TOTAL & $19.389,2$ & 94,08 & 313.398 & 65,84 \\
\hline
\end{tabular}

Nota: Los porcentajes están calculados sobre el total de Seculares.

Fuenle: R. Particulares Catastro Ensenada. Guadix.

Entre el numeroso grupo de miembros del E. Llano sólo tienen rentas superiores a 10.000 reales cuatro propietarios: Nicolasa Merino, María de Vera, Antonia Moreda y Juan Herrasti, que formarían parte de la élite de la época, si bien al tratarse de propietarios que viven fuera de la ciudad, en Granada, y por tanto, desconocemos su situación social, especialmente llamativa en el caso de Nicolasa Merino, con una de las rentas más elevadas de todo el término, sólo superada por la de la Catedral. Es la propietaria del cortijo de Fuente Caldera, pudiendo tratarse de un miembro de la nobleza granadina, hecho que no hemos podido comprobar; sin embrago, al no indicar nada al respecto el Catastro nos hemos inclinado por considerarla miembro del E. Llano, ya que 
es bien conocida la meticulosidad con que fue elaborado. En todo caso estamos ante propietarios absentistas, excepto María de Vera, que controlaban el $85 \%$ de las tierras del Estado Llano, produciéndose también una fuerte concentración de la propiedad.

La mayoría de los propietarios de este grupo son pequeños y muy pequeños propietarios, y por tanto, la renta de sus tierras, inferior a 600 reales, no les permite vivir de ella, sino que tienen que trabajar como jornaleros o arrendar tierras de otros para sobrevivir. Estos son la mayoría, el $75 \%$ y se reparten una porción mínima de tierras el $5 \%$ y el 9,7\% de la riqueza, desequilibrio que se explica porque se trata de pequeñas extensiones de tierra (el $56 \%$ menos de $1 / 2 \mathrm{Ha}$.; y el $23 \%$ entre $1 / 2$ y $1 \mathrm{Ha}$.), pero de regadío: viñas y hortalizas, «sin intermision», cuya producción es de por sí elevada, sin olvidar el esmerado cultivo a que se ven sometidas.

Estamos ante una estructura de la propiedad claramente minifundista entre los propietarios del Estado Llano, ya que el $79 \%$ tiene menos de $1 \mathrm{Ha}$, y además se encuentran parceladas, por lo que a los males del minifundio hay que añadir las derivadas del fraccionamiento de la propiedad en parcelas minúsculas, que origina un lamentable minifundismo parcelario, doblemente pernicioso.

La Ciudad de Guadix poseía un importante patrimonio (52,5\% del total municipal) integrado por los bienes de propios y los de comunes, básicamente formados por tierras inútiles. Los bienes de propios los integran los cortijos de Dehesas y la Rambla de los Ciruelos, ambos arrendados, el primero en 400 fanegas de trigo y 250 de cebada y el segundo en 50 de trigo y 50 de cebada cada año. El resto eran bienes de comunes, es decir a disposición de todos los vecinos para recoger leña, para pastos, para recoger esparto, y bellota para alimentar a sus animales. Sin duda, cumplían una función social importante para las economías más modestas, para las que constituía un complemento importante. Las roturaciones sucesivas ante el hambre de tierras van a ir diezmando estos bienes, hasta que la desamortización de Madoz permita sacarlos a pública subasta para su venta o bien fueran a engrosar patrimonios de particulares. En la actualidad, el cortijo de Dehesas, junto con otros pertenecientes a Guadix en el siglo XVIII, ha constituido un municipio nuevo, que carece de bienes municipales. Tampoco los tiene el municipio de Alicún de Ortega, hecho que confirma su pase a manos de particulares.

Tras analizar las características de los propietarios según los criterios vigentes en el s. XVIII, creemos necesario para que nos sirva de elemento comparativo con otras áreas geográficas ya estudiadas, realizar un análisis global de la estructura de la propiedad en Guadix, y en base al criterio superficie de las propiedades, pese a las deficiencias que conlleva, ya que a la postre lo que importa no es la superficie detentada, sino la renta producida. En el cuadro 
IX reflejamos estas magnitudes, en pequeños grupos o categorías, para a partir de ellos obtener los grandes grupos, que representan a la pequeña, mediana y gran propiedad; teniendo en cuenta que consideramos mediana propiedad a todas aquéllas que tienen una extensión comprendida en el intervalo 10-100 Has.

CUADRO IX

ESTRUCTURA DE LA PROPIEDAD EN 1752

\begin{tabular}{|c|c|c|c|c|c|c|}
\hline \multirow{2}{*}{ Intervalos (Grupos) } & \multicolumn{2}{|c|}{ Propietarios } & \multicolumn{2}{|c|}{ Superficie (Has.) } & \multicolumn{2}{|c|}{ Riqueza en rs. } \\
\hline & Total & $\%$ & Total & $\%$ & Total & $\%$ \\
\hline 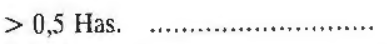 & 101 & 29,5 & 27,81 & 0,11 & 13.520 & 1,4 \\
\hline 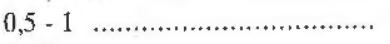 & 49 & 14,3 & 36,58 & 0,14 & 13.877 & 1,4 \\
\hline $1-5$ & 109 & 31,9 & 251,08 & 0,95 & 107.101 & 11,1 \\
\hline $5-10$ & 25 & 7,3 & 166,28 & 0,63 & 77.699 & 8,1 \\
\hline $10-20$ & 19 & 5,5 & 280,31 & 1,07 & 85.299 & 8,8 \\
\hline $20-50$ & 16 & 4,7 & 510,60 & 1,95 & 139.311 & 14,4 \\
\hline 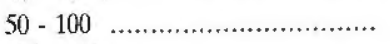 & 10 & 2,9 & 721,94 & 2,76 & 85.036 & 8,8 \\
\hline $100-250$ & 4 & 1,2 & 720,87 & 2,76 & 131.907 & 13,7 \\
\hline $250-500$ & 2 & 0,6 & 811,11 & 3,10 & 28.253 & 2,9 \\
\hline 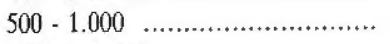 & 3 & 0,9 & $2.242,10$ & 8,58 & 97.363 & 10,1 \\
\hline 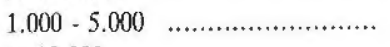 & 3 & 0,9 & $6.675,00$ & 25,55 & 131.778 & 13,6 \\
\hline$<10.000$ & 1 & 0,3 & $13.672,00$ & 52,35 & 54.302 & 5,6 \\
\hline TOTAL $\left({ }^{*}\right)$ & 342 & 100,0 & $26.116,15$ & 100,00 & 965.450 & 100,0 \\
\hline
\end{tabular}

(*) La diferencia con la superficie total del cuadro III se debe al error que se acumula al realizar la conversión a has.

Fuente: R. Particulares Catastro Ensenada. Guadix.

En el gráfico III representamos la relación entre propietarios, superficie detentada y riqueza para los tres grandes grupos en las barras verticales de la izquierda y en los rectángulos de la derecha los tipos de cultivo, según porcentajes, que posee cada categoría. Del análisis del cuadro IX y del gráfico III deducimos las siguientes conclusiones:

a) Nos encontramos ante una estructura de la propiedad claramente minifundista, pues el $83 \%$ de los propietarios tienen menos de 10 has., y se reparten tan sólo el 1,83\% de la superficie, si bien en cuanto a la riqueza poseída se produce un salto cualitativo y cuantitativo importante al controlar el $22 \%$, debido a que sus tierras son de buena calidad (el $20 \%$ del regadío, siendo la mayoría de producción anual, el 72,3\%, y de ellas son viñas la mayor parte).

Realza aún más el carácter minifundista el hecho de que las propiedades de menos de $1 \mathrm{Ha}$. son el grupo más numeroso 150, que suponen el 43,8\% del total y de ellas el $67 \%$ son inferiores a 1/2 Ha., expresión más clara del minifundismo agravado aún más, si cabe, por la dispersión parcelar. 
Las propiedades de 1-5 Has. de superficie son 109, el 31,09\% del total, repartidas prácticamente a partes iguales entre seculares y eclesiásticos. El subgrupo más reducido, con el 7,3 \% de las propiedades, corresponde al intervalo superior de la pequeña propiedad, el que podríamos considerar pequeñamediana; es decir, el más viable económicamente dentro de este grupo, en el que la propiedad mediana llega a 2 Has. (1,83 has., media muy cercana a la muy pequeña propiedad).

Por tipos de tierras hay que señalar el predominio de regadío con 390 has., el $81 \%$; en cambio el secano supone el $4,5 \%$ y las tierras inútiles el $14,5 \%$ restante. La alta productividad, y por tanto, el alto porcentaje de la riqueza que les corresponde se debe a este predominio del regadío. A una disminución de las tierras de regadío, en beneficio del secano y de las infructíferas, como comprobaremos en la mediana y gran propiedad.

b) La mediana propiedad, está estadísticamente comprendida entre 10-100 Has. de extensión, se extiende al 13,2\% de las propiedades, que controlan el 5,8 \% de la superficie, y el 32,1\% de la riqueza producida, fuerte desequilibrio entre superficie y riqueza que se explica por la presencia de un elevado porcentaje de tierras de regadío, el 33,6 \% del total de regadío.

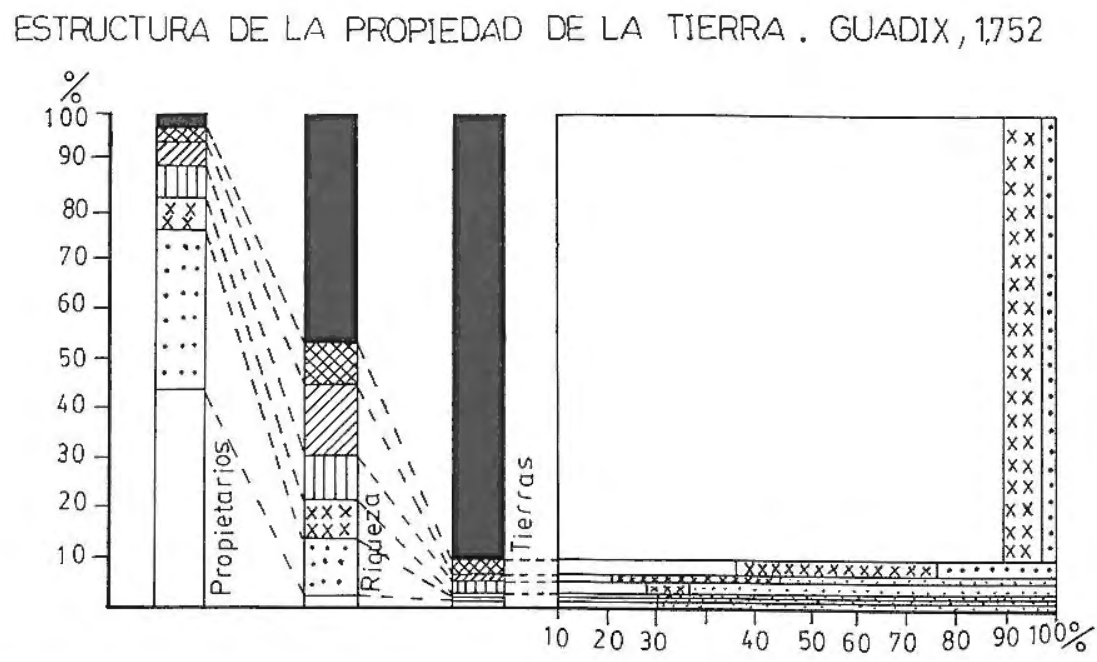

GRUPOS DE PROPIETARIOS

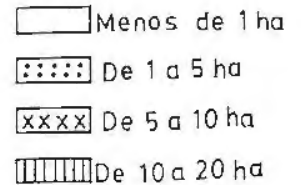

WIIIIIDe 10 a 20 ha

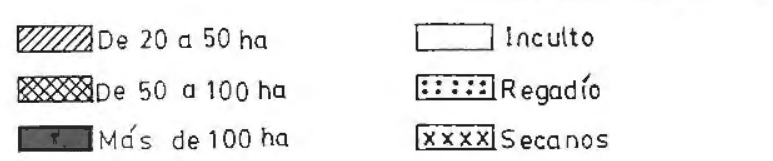

Graíco no3 Fuente C.Ensenada 
El intervalo inferior, de 10-50 has., es el más representativo de la mediana propiedad, suponiendo el 10,2\% del total, si bien son más abundantes las propiedades de menos de 20 has., aunque la propiedad media del grupo se sitúa en 33 has., aunque la propiedad media del grupo se sitúa en 33 has. Este grupo debería ser el más numeroso si estuviéramos ante una estructura de la propiedad más racional, sin los fuertes impactos que en ella originó la repoblación, las «mercedes reales» y las posteriores acumulaciones por compras, donaciones, en manos de unos pocos propietarios nobles y eclesiásticos.

De las 1.512,9 has. que acaparan los medianos propietarios, 668 has. son de regadío, el $44 \%$; mientras que los secanos son el $32,6 \%$ del total y el resto $23,3 \%$ de tierras inútiles. Con respecto a la pequeña propiedad el regadío ha reducido su presencia en casi un $40 \%$; en cambio se han incrementado sustancialmente los porcentajes de los secanos y de las tierras infructíferas.

No existía, por tanto, una mediana propiedad consolidada, capaz de dar ocupación a un importante número de agricultores, que se hubieran convertido enla base de la producción y de la población activa, y que hubiera permitido el desarrollo de una agricultura más racionalizada y productiva, contribuyendo a desarrollar prósperas economías que fomentarían la riqueza y la población del estado ${ }^{11}$ como se plantearon los consejeros mercantilistas de Carlos III, convencidos de que en ellos encontrarían la base de la prosperidad del país.

c) La gran propiedad, considerando como tales las que tienen más de 100 Has., está presente en Guadix, aunque sólo suponen el 3,8 \% del total, si bien acaparan el $92,4 \%$ de la superficie municipal, aunque su riqueza resulta muy inferior a este porcentaje, bajando hasta el $45,9 \%$, debido a la presencia de grandes extensiones de tierras inútiles. En el cuadro $\mathrm{X}$ recogemos los datos correspondientes a los trece propietarios mayores del término de Guadix, todos con más de $100 \mathrm{Has}$, indicando los porcentajes que sobre el total de tierras y de la renta municipal acaparan. Debemos resaltar la gran importancia que tiene las propiedades de la ciudad desde el punto de vista cuantitativo, si bien cualitativamente tienen poco valor, al tratarse de terrenos incultos y escasamente productivos.

De ellos, siete son eclesiásticos, instituciones fundamentalmente, cuatro nobles, una propiedad pública, la Ciudad, y otra privada de origen social desconocido.

Por cultivos, de las $24.221,5$ has., que acaparan, son tierras inútiles el 87,9 $\%$, propiedad en su mayoría de la ciudad, con 14.423 has., de Nicolasa Merino, con 2.414 has., de la Compañía de Jesús, con 2.397; y del Marqués de cortes, con 952 has. Son tierras de secano 2.006 has., el 8,3\%, y de regadío 929 has., el 3,8\% restante.

11. HERR, R. «España y la revolución del siglo XVIII», Capítulo IV in extenso, pág. 94. 
Destaca, por tanto, el escaso porcentaje del regadío en relación al total de tierras de este grupo; sin embargo, con respecto al total de regadío acaparan casi la mitad (47\%), fundamentalmente distribuido entre las propiedades de menos de 500 has., siendo la Catedral de Guadix el que más tierras de regadío posee (132,7 has.), seguido del Convento de Santa Clara de Guadix (110,8 has.) y de la Compañía de Jesús (103,7 has.).

\section{CUADRO X}

GRANDES Y MUY GRANDES PROPIETARIOS. GUADIX, 1752

\begin{tabular}{|c|c|c|c|c|}
\hline \multirow{2}{*}{ Nombre propietario } & \multicolumn{2}{|c|}{ Superficie (Has.) } & \multicolumn{2}{|c|}{ Renta br. (Reales) } \\
\hline & Total & $\%\left({ }^{*}\right)$ & Total & $\%\left({ }^{*}\right)$ \\
\hline Ciudad de Guadix . ....................... & $13.672,00$ & 52,5 & 54.302 & 5,6 \\
\hline Nicolasa Merino . .......................... & $2.963,26$ & 11,3 & 60.361 & 6,3 \\
\hline Compañía Jesús .......................... & $2.642,25$ & 10,1 & 41.278 & 4,3 \\
\hline 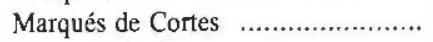 & $1.071,99$ & 4,1 & 30.132 & 3,1 \\
\hline 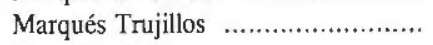 & 892,09 & 3,4 & 36.722 & 3,8 \\
\hline 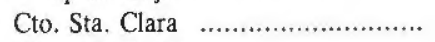 & 834,75 & 3,2 & 53.173 & 5,5 \\
\hline 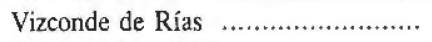 & 515,25 & 1,9 & 7.467 & 0,8 \\
\hline 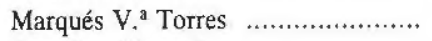 & 456,02 & 1,7 & 17.012 & 1,7 \\
\hline Cto. Sta. Clara-Baza . .................. & 355,09 & 1,3 & 11.241 & 1,2 \\
\hline 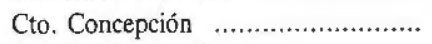 & 227,59 & 0,8 & 37.405 & 3,9 \\
\hline 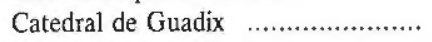 & 176,34 & 0,7 & 72.840 & 7,5 \\
\hline 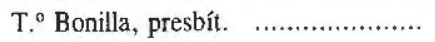 & 163,16 & 0,7 & 6.119 & 0,6 \\
\hline Cto. Sto. Domingo ....................... & 153,83 & 0,6 & 15.541 & 1,6 \\
\hline TOTAL & $24.121,55$ & 92,4 & 443.605 & 45,9 \\
\hline
\end{tabular}

$\left({ }^{*}\right)$ Los porcentajes están calculados sobre el total municipal.

Fuente: R. Particulares Catastro Ensenada. Guadix.

En síntesis, se trata de una estructura polarizada, en la que el $83 \%$ de los propietarios tan sólo posee el 1,8\% de la superficie, de ahí el hambre de tierras, mientras que el 3,8\% de los propietarios, nobles y eclesiásticos fundamentalmente, acaparan el $92,4 \%$ de la tierra.

Estructura muy desigual fruto de circunstancias históricas que tienen su origen en el reparto de tierras posterior a la conquista y expulsión de los musulmanes y en la posterior repoblación y repartimiento que se hizo de las heredades no respetando el plan inicial de asentar a 2.000 familias, debido a que los Reyes concedieron grandes mercedes, que inician el desarrollo de la gran propiedad, que se va incrementando por compras, usurpaciones, cesiones, donaciones a las instituciones religiosas,... a lo largo del siglo XVII y principios del XVIII.

Queda bastante bien definida la estructura estamental de la sociedad accitana, en la que los dos estamentos privilegiados acaparan la mayor parte de la 
tierra formando grandes propiedades, en algunos casos inmensas. No podemos olvidar la importancia del sector público, en este caso los Bienes del Común de la Ciudad (comunes y propios), pero con una escasa superficie de tierra productiva, en relación al total de tierras poseídas. Además hemos constatado la presencia entre los propietarios de un nuevo grupo que surge con fuerza y que empieza a alterar la base de los privilegiados, mediante el acceso a la propiedad de la tierra, que era el símbolo más claro de poder en el siglo XVIII.

En el polo opuesto, una mayoría de la población activa se distribuye una parte insignificante de la tierra, originando un fuerte minifundismo, que también tiene su origen en la repoblación, y que incluso se da en el secano, tierras de una productividad muy baja, ya que se cultivaban al tercio, donde las propiedades deberían ser más extensas.

Si consideráramos para el análisis de la estructura de la propiedad las tierras productivas (regadío y secano), excluyendo las improductivas, según el criterio de la época, no varían prácticamente los resultados, si bien la extensión de las propiedades disminuye sensiblemente, pasando la mayor propiedad a tener 549 has. (Nicolasa Merino), frente a las 13.772 que tenía la Ciudad considerando también las tierras improductivas. De esta forma, las pequeñas propiedades supondrían el 83,2\%, controlando el 9,7\% de la tierra y el 23,7 de la superficie.

La gran propiedad representaría el $2,9 \%$ acaparando el $24,4 \%$ de la tierra y el $21,2 \%$ de la riqueza.

La mediana propiedad estaría integrada por el 13,7 \% de los propietarios, que controlan el 30,9\% de la tierra productiva y el $55 \%$ de la riqueza.

Es decir, la estructura de la propiedad en Guadix en el siglo XVIII, tanto considerando las tierras improductivas como excluyéndolas, se caracteriza por la concentración en manos de unos pocos de la mayor parte de la fuente de riqueza más importante de la época: la tierra; y por la existencia de un numeroso grupo de propietarios pequeños y muy pequeños que apenas tienen lo suficiente para no morir de hambre, por lo que se ven obligados a llevar tierra en arrendamiento o bien a proletarizarse trabajando las tierras de los grandes. Al excluir las tierras improductivas se aprecia un incremento de la fuerza de la mediana propiedad, que si bien permanece inalterable desde el punto de vista de los propietarios, con un porcentaje idéntico, desde el punto de vista de la tierra y de la riqueza incrementa netamente su participación en la distribución municipal. La tierra controlada por la mediana propiedad pasa a ser el $30,9 \%$ (frente al 5,7\%, incluyendo las tierras inútiles) y la riqueza se incrementa hasta el $55 \%$ (frente al $32 \%$ ). A la dualidad entre grandes y pequeños propietarios se une otra no menos perniciosa, la dualidad entre tierras vinculadas y tierras libres como veremos en el capítulo dedicado al estudio de la propiedad amortizada y vinculada. 
Una de las características que más llama la atención de la distribución de la propiedad en el siglo XVIII es la existencia de un importante número de ellas que no podían ser vendidas, cedidas... es decir, estaban fuera del circuito comercial, sometidas a unas normas que hoy pueden parecernos fuera de lugar, pero en aquélla coyuntura económica respondían a unas necesidades muy concretas y a una forma de entender la propiedad muy peculiar. Surgen dos formas, fundamentalmente, de detraer las propiedades del sistema comercial libre: LA IGLESIA instituye la propiedad en manos muertas, por la que una parte considerable de las tierras que pasan a su poder son detraídas de la compra-venta al adscribirlas a determinadas funciones religiosas o a determinadas instituciones, constituyéndose en propiedades amortizadas, que eran usufructuadas por el individuo que ejercía el cargo al que estaban adscritas, o bien por la institución que las detentaba. La exención fiscal, privilegio de la Iglesia fue una razón imperante a la hora de realizar estas amortizaciones, además muchos particulares ante el incremento de la presión fiscal de la Corona y de los señores o por el simple deseo devoto de asegurarse unos servicios eclesiales tras su muerte, hicieron proliferar las donaciones de tierras y otros bienes a la iglesia.

Por su parte, los nobles instituyeron el «mayorazgo» para defender su patrimonio de la división que originaban las herencias, con lo que el título perdía parte del poder en que se fundamentaba, y evitar que futuros herederos poco responsables pudieran dilapidar la base en la que sustentaba el título, el prestigio de la casa a la que pertenecían, que como sabemos era básicamente las propiedades rústicas.

No podemos olvidar que-había una tercera fórmula de detraer tierras del mercado, propiciada por el sector público, a fin de asegurar al municipio unos ingresos seguros con los que hacer frente a los gastos más imprescindibles, apareciendo así los bienes comunales, que eran de dos tipos: comunes y propios, según fuesen utilizados por todos los pertenecientes al municipio, o fuesen arrendados a particulares a cambio de un pago en metálico o en especie.

El resto de tierras eran libres, podían ser vendidas, cedidas... pero eran un porcentaje muy reducido a mediados del siglo XVIII, como se desprende del análisis que realizaremos a continuación.

Las tierras de la Iglesia las clasifica el Catastro en dos tipos: las poseídas a título individual por los miembros del clero, y las amortizadas en manos de instituciones, conventos, capellanías, memorias, beneficios, que constituyen el grueso del grupo. Este proceso amortizador que tiene su origen en la presión fiscal creciente por parte de la corona y en la importancia del hecho religioso en el Antiguo Régimen determinó que a mediados del siglo XVIII una parte de las tierras hubiesen ido a parar a manos de la Iglesia. En efecto, este proceso queda fielmente reflejado en el Catastro de Ensenada, en el que queda 
reflejado un espectacular incremento de las propiedades de la Iglesia, quedando fuera del circuito comercial por estar amortizadas en manos muertas. Lo cual no quiere decir que no fuesen productivas, sino más bien al contrario, pues hemos visto cómo eran de las mejor explotadas, bien directamente por algunos conventos, o bien - práctica más generalizada- cedidas en arrendamiento a colonos o aparceros.

Sobre estas tierras y otras que se amortizarían hasta mediados del siglo XIX, actuaría el proceso desamortizador, que en oleadas sucesivas fue sacando a la venta en pública subasta el patrimonio de la Iglesia, los mayorazgos nobles y los bienes de propios a lo largo del siglo XIX.

En Guadix, las tierras amortizadas en manos de la Iglesia, totalizan 4.622,2 has., el $84 \%$ del total de eclesiásticos, y producían por valor de 305.293 rs., el $62,4 \%$ de la renta de estos propietarios; resultando un valor medio por ha. de tierra de 69,5 rs. y un valor medio por finca de 4.902 rs. anuales. Para su estudio los hemos clasificado en dos grupos:

a) Propiedades institucionales, en las que se incluyen las tierras en posesión de la Catedral, Hospital Real, Conventos de religiosos/as, hermandades, obras pías, capellanías vacantes, cofradías, beneficios y ermitas; totalizando 35 propiedades de muy variada extensión, que van desde la insignificante finca de 0,02 has., hasta la más grande de la Compañía de Jesús con más de 2.600 has. Pese a esta diversidad, se constata una fuerte concentración, ya que siete propiedades de este grupo acaparan el $91,9 \%$ de la superficie y el $85,8 \%$ de la riqueza, desequilibrio explicado por la enorme proporción de tierras inútiles de estas grandes propiedades. En el polo opuesto se sitúan otras tantas propiedades, que no producen ni 100 rs. de renta bruta, y cuyas superficies oscilan entre 1 y 3 fanegas $(0,23$ y 0,7 has.).

b) Bienes pertenecientes al clero secular, que en el Catastro aparecen reflejados como «beneficial»; es decir, son aquéllos detentados en razón del cargo que se ejerce: capellanías, beneficios... y consignados en la cuenta de valor diferenciándolos de los de propiedad particular «patrimonial». Este subgrupo lo integran 21 propiedades, que totalizan 56,69 has., el $1,2 \%$, y producen 21.210 rs., el $6,5 \%$. Se trata de pequeñas propiedades, siendo la media de 2,7 has., a excepción del beneficio que disfrutaba Antonio de Mesa, presbítero, que tenía una superficie de 12 has.

Es difícil abordar un análisis riguroso de la propiedad vinculada porque el Catastro no incluye anotaciones detalladas sobre este particular en el caso de los propietarios seculares. Al no decir nada de forma explícita se puede enten- 
der que por defecto todas las tierras en manos de nobles estaban vinculadas al título, conclusión que nos parece excesiva dado la existencia de muy pequeñas propiedades en este colectivo, como hemos puesto de manifiesto en el apartado sobre los bienes de la nobleza, nos lleva a pensar que no todos estarían vinculados, si bien, era una pretensión bastante generalizada, incluso entre los plebeyos, primer paso, para después conseguir un título de nobleza, comprándolo a la Corona.

La vinculación era, en opinión de R. HERR, uno de los males que afectaba a la agricultura española del siglo XVIII, porque «creaba una clase numerosa de ociosos e impedía que la tierra se negociase» y además las tierras quedaba mal cultivada porque «la mentalidad de los titulares de vínculos era despreciar el trabajo manual, por lo que malvivían de las rentas de su mayorazgo» ${ }^{12}$.

No parece ser ésta exactamente la situación de las tierras de nobles de Guadix, porque no aparecen censados hidalgos y, por tanto, nos inclinamos a pensar que sólo las grandes propiedades de la nobleza estarían amortizadas y grandes propiedades de la nobleza estarían amortizadas y vinculadas al título. Nada podemos deducir de la situación de muchos pequeños patrimonios que dado lo generalizado de la época podrían estar vinculados; por tanto, los cálculos de la propiedad vinculada están claramente calculados por defecto, en razón de las causas explicitadas más arriba.

De ser así las cosas, la propiedad vinculada en manos de la nobleza estaría integrada por cinco propiedades con título, todas forasteras excepto el Marqués de Cortes, y excluyendo la de los Marqueses de Diezma y de Las Dos Fuentes, por no sumar ni una fanega de tierra entre ambos; el resto de las propiedades que hemos incluido entre las de la nobleza aparecen con el título de caballero o como miembro del «estado noble», integrados por los regidores de la ciudad, cuya situación desde este punto de vista no aparece explicitada. ¿Es posible que algunas de estas propiedades estuvieran también vinculadas? No nos es posible saberlo sin disponer de las escrituras de tales propiedades, pero de ser así los datos globales serían los incluidos en el apartado donde hemos analizado los bienes de la nobleza.

En principio, nos inclinamos por pensar que la propiedad vinculada estaría ligada a la existencia de títulos de cierta importancia aunque ninguno es de los grandes de España, y que se reducen a cinco propiedades, que totalizan $2.966,36$ has., el $92,4 \%$ de las tierras de la nobleza, y con respecto al total municipal suponen el $11,3 \%$ de la tierra y el $11,9 \%$ de la riqueza. Similares porcentajes se daban en el Sur de Córdoba, según ha calculado el profesor ORTEGA ALBA ${ }^{13}$.

12. HERR, R. Op. cit., pág. 77.

13. ORTEGA ALBA, F. «El sur de Córdoba. Estudio de Geografía agraria», ed. Monte de Piedad y Caja de Ahorros de Córdoba, 1975. Vol, II, capítulo X. 
Finalmente, también estaban fuera del circuito comercial las tierras del municipio de Guadix y del Pósito Real, como instituciones públicas, que totalizan 13.702 has., el 52,6 \% del total municipal, si bien la inmensa mayoría son tierras inútiles por naturaleza, en concreto 13.432 has.; cuya importancia de cara a la desamortización civil es mínima, desde el punto de vista agrícola, aunque no desde el económico para las familias accitanas con más bajos niveles de rentas.

En total, y posiblemente calculadas por defecto, las tierras amortizadas, vinculadas, amayorazgadas, eran la inmensa mayoría, 21.390,7 has., el 81,6 \%, aunque de ellas el $88 \%$ eran inútiles por naturaleza y el resto incluía importantes extensioncs de regadío; por tanto, fuera del circuito comercial estaba la parte más importante de la tierra accitana, lo que provocó, como en el resto de la Corona de Castilla, una clara falta de tierras en el mercado y como consecuencia un incremento del precio de las rentas de la tierra ${ }^{14}$.

Las críticas de los ilustrados a estas formas de propiedad de la tierra fueron virulentas, especialmente a las amortizadas en manos muertas, por parte tanto de Jovellanos como de Campomanes. En concreto, éste último en su obra «Tratado de la Regalía de la amortización...» (1775), apelando a razones jurídicas contribuyó al estudio de las causas de este fenómeno y al inicio de las disposiciones desamortizadoras, aceleradas tras el Informe de JOVELLANOS (1784), que incidía en las mismas soluciones, y debido a las necesidades de la hacienda real. En general, todos los economistas españoles del siglo XVIII coincidían en la necesidad de poner coto a los progresos en la acumulación de la propiedad territorial en manos de la iglesia y no se contentaron en señalar los efectos perniciosos de la amortización en cuanto a la decadencia y despoblación del país, sino que se esforzaron en demostrar la ilegalidad de los bienes amortizados en manos del clero regular y secular ${ }^{15}$.

De igual forma se atacó a los mayorazgos, y en concreto, JOVELLANOS, pese a reconocer a la nobleza los altos servicios prestados al estado y el derecho que le asiste a la retención de un patrimonio familiar que fundamente su situación preeminente en la sociedad, pero es partidario de reducirlos al mínimo y ante todo, de derogar las leyes que permitan vincular la propiedad territorial... Aconseja la necesidad de dar a los mayorazgos la licencia de ceder en enfiteusis los bienes vincualdos ${ }^{16}$.

Las críticas tampoco faltaron a la situación de los bienes municipales, produciéndose una doble corriente en cuanto a la forma de proceder a su liquidación: por una parte los que defendían que se les debería ceder formando ex-

14. VICENS VIVES, J. «Historia de España y América, social y económica», ed. Vicens Vives, Barcelona, 1979, Vol. IV, 3. ${ }^{a}$ reedición, pág. 30.

15. VICENS VIVES, J. Op. cit., pág. 16.

16. VICENS VIVES, J. Op. cit, pág. 23. 
plotaciones colectivas; así opinaban Aranda, Floridablanca, y Olavide; organizadas en cotos familiares fijos e inalienables; y por otra los defensores de la solución individualista, como JOVELLANOS, que a la postre fue la que se tomó en el siglo XIX, cuando se produjo la desamortización ${ }^{17}$.

Por la importancia cuantitativa y cualitativa de las tierras amortizadas, vinculadas... no cabe la menor duda de que la polarización propiedad libre y propiedad vinculada es uno de los elementos más característicos de la estructura de la propiedad del s. XVIII, así lo hace constar también J. CRUZ VILLA$\mathrm{LON}^{18}$ al hablar de la dualidad entre propiedad libre/vinculada, considerando que las «diferencias existentes en la estructura agrarias están mucho más relacionadas con las categorías de propietarios ausente/residente y propiedad libre/vinculada, que con los estamentos tradicionalmente considerados...».

Esta afirmación nos introduce en otro de los aspectos más problemáticos de la agricultura accitana: la existencia de un importante número de fincas, cortijos enteros, en manos de propietarios forasteros; es decir nos lleva a considerar el problema del absentismo, tan característico de la Andalucía Bética, una de cuyas poblaciones ha estudiado CRUZ VILLALON, pero que en Guadix no llega a alcanzar los niveles puestos de manifiesto por la mencionada autora y por otros trabajos sobre el latifundio, como el colectivo dirigido por M. ARTOLA.

\section{EL ABSENTISMO}

La existencia de propietarios forasteros es también un rasgo diferencial de la propiedad accitana, y que aparece muy ligado a la gran propiedad noble y eclesiástica, aunque el mayor número de propietarios forasteos son de la provincia de Granada. En Guadix existían 40 propietarios forasteros en los volúmenes estudiados, de ellos 24 eclesiásticos, distribuidos por áreas geográficas de la siguiente forma: de la comarca de Guadix y del marquesado del Cenete, 11; del resto de la provincia de Granada, 22 (siendo la mayoría de ellos residentes en la capital, 17); de Almería, 3; y los 4 restantes de otras ciudades españolas (Valladolid, Málaga, Canarias...).

Si bien el número de propietarios forasteros no es excesivamente elevado, el $11,7 \%$ del total, sí lo es en cambio la superficie detentada, especialmente de algunos grandes propietarios, con rentas superiores a los 10.000 rs.

Estos nueve propietarios forasteros, con rentas superiores a 10.000 rs., excepto el Vizconde de Rías, que hemos incluido por poseer un extenso patrimo-

17. VICENS VIVES, J. Op. cit., pág. 21.

18. CRUZ VILLALON, J. «Propiedad y uso de la tierra en la Baja Andalucía: Carmona, siglos XVIII-XX», ed. Ministerio de Agricultura. Madrid, 1980, pág. 132. 
nio rústico, acaparan el 20,3\% de la tierra accitana y se llevan el $20,8 \%$ de la renta producida. Sin duda el patrimonio más extenso es el de Nicolasa $\mathrm{Me-}$ rino, propietaria del cortijo de Fuente Caldera, con una superficie de 2.963,26 has. entre secanos y tierras inútiles, y con la renta más elevada de toda la ciudad, tras la disfrutada por la Catedral. Los miembros de la nobleza además tenían importantes propiedades en municipios próximos, como es el caso del Marqués de los Trujillos, D. Alfonso de Bohórquez, mayor hacendado en Purullena, Gorafe y el Cortijo de Uleylas Bajas, perteneciente a la jurisdicción de Guadix, y además ejercía la jurisdicción en Albuñán, Gorafe ${ }^{19}$. En Fonelas poseía 93,2 ha. de regadío.

\section{CUADRO XI}

PROPIETARIOS FORASTEROS CON MAS DE 10.000 RS. DE RENTA

\begin{tabular}{|c|c|c|c|}
\hline Propietario & Residencia & Superficie (Ha.) & Renta (Ts.) \\
\hline Nicolasa Merino ..................... & Granada ....................... & $2.963,26$ & 60.365 \\
\hline 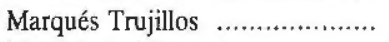 & Valladolid ....................... & 892,09 & 36.722 \\
\hline Marqués V.a Torres ................. & Granada ......................... & 456,02 & 17.012 \\
\hline 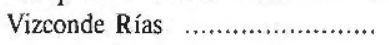 & Granada ...................... & 515,23 & 7.467 \\
\hline Cto. Sta. Clara ........................... & 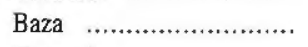 & 355,09 & 11.241 \\
\hline Antonia Moreda & 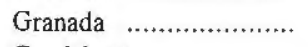 & 51,53 & 14.897 \\
\hline 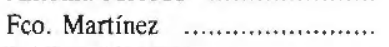 & Guadahortu. ................. & 20,61 & 12.432 \\
\hline J. Pérez Herrasti .................... & Granada ......................... & 34,22 & 16.990 \\
\hline Marqués Villalegre ................... & Granada ....................... & 31,03 & 23.638 \\
\hline TOTAL $\ldots . .$. & (n) & $5.319,06$ & 200.746 \\
\hline
\end{tabular}

Fuente: R. Particulares Catastro Ensenada.

El Marqués de Villanueva de las Torres, D. Pedro Afán de Rivera, que recibe 15 fanegas de trigo y 8 de cebada por cada una de las doce suertes y 93 gallinas como censo por «razón de volar» y del secano recibe una renta que oscila entre el $5 .^{\circ}$ y el $6 .^{\circ}$ de su producción. Es el mayor y único hacendado de Huélago, villa de la que es Marqués. Además posee propiedades en Benalúa y en Fonelas.

Estos datos ponen, una vez más manifiesto, que circunscribir el estudio de la propiedad a un sólo municipio lleva consigo un error intrínseco bastante deformador de la realidad, ya que un pequeño propietario en un municipio puede ser grande o muy grande en el municipio próximo; o en el caso de los grandes es muy frecuente que tengan sus propiedades distribuidas en varios municipios. El estudio global de los datos de la comarca de Guadix, aunque también lo será por definición incompleto, será el objetico a acometer para la realización de la Tesis Doctoral.

19. ARTOLA, Miguel y otros, op. cit., pág. 60 . 


\section{CONCLUSIONES}

1) El Catastro del Marqués de la Ensenada es una fuente de estudio excepcional para conocer las características del paisaje agrario durante el s. XVIII.

2) El término actual de Guadix es muy similar al que en el s. XVIII se llamaba «término de la campana»; habiéndose producido una considerable disminución de los territorios sobre los que ejercía su jurisdicción, integrados en su extenso Corregimiento.

3) En el término de Guadix hay un claro predominio de las tierras incultas, llamada «inútiles por naturaleza», que suponen el $82,7 \%$, mientras que las cultivadas suponen el $17,3 \%$ restante.

4) De las tierras cultivadas eran de regadío el $44,3 \%$ y de secano el $55,7 \%$ restante. El regadío agrupaba a tierras de distintas clases y calidades, predominando las de «año y vez», que suponían el 59,6 \% del regadío; es decir, más de la mitad de las tierras de regadío producían una cosecha cada dos años.

5) Los cultivos predominantes eran los cereales: trigo (más del $50 \%$ de las tierras) y cebada en regadío; mientras que el secano se cultivaba exclusivamente de centeno. Estamos ante unas tierras que bien podríamos llamar de «pan llevar». Completa la distribución de cultivos las leguminosas de consumo humano y las plantas industriales, como el lino y el cáñamo destinados a la producción de sogas.

6) La ganadería completaba la renta agraria y no tuvo un desarrollo independiente, produciéndose una simbiosis entre ambas actividades y no una oposición frontal como en otros lugares del país.

7) Los regímenes de tenencia más generalizados eran la aparcería y el colonato, concontratos de arrendamiento de corta duración, que oscilan entre 3 y 6 años, y con rentas en especie para aprovechar la subida de los precios.

8) La iglesia controlaba el $21 \%$ de las tierras, pero su dominio era selectivo, ya que controlaba el 53,2\% del regadío, que son las mejores tierras. Las propiedades eclesiásticas están muy desigualmente distribuidas, siendo el mayor propietario la Compañía de Jesús, con 2.642,5 has., aunque la inmensa mayoría son tierras incultas. Es la Catedral de Guadix la que domina y controla las mejores tierras de regadío próximas a la ciudad, junto con algunos conventos.

9) Los propietarios seculares, que suponen el 61,4\% controlan el $79 \%$ de la superficie total. Es éste un colectivo muy heterogéneo, con grandes diferencias sociales y económicas, pues en el se integran la nobleza, y el Estado Llano. De hecho el Estado Llano que como colectivo supone el 90 \%, sólo controla el 17,9 \% de la superficie del grupo, si bien su riqueza se eleva al 50,7 \% . El Estado Llano estaba integrado en su mayoría por pequeños y muy peque- 
ños propietarios, con rentas inferiores a 600 rs. y superficies inferiores a 1 ha. en un $79 \%$ de los casos, situación que les obliga a trabajar como jornaleros o a arrendar tierras.

10) La estructura de la propiedad es claramente minifundista, pues el $83 \%$ de las propiedades tienen menos de 10 has. y se reparten el 1,83\% de la superficie y el $22 \%$ de la riqueza. De estas propiedades el $43,8 \%$ tienen menos de $1 / 2$ ha. Podemos además afirmar:

- No existió una mediana propiedad consolidada capaz de dar trabajo y una renta digna a un numeroso grupo de trabajadores capaces de desarrollar una agricultura próspera.

- Las grandes propiedades acaparan el 93,4 \% de la superficie, aunque su riqueza solo llega hasta el $45,9 \%$, que se reparten el 3,8\% de la población. La mayoría estaban amortizadas, vinculadas y cultivadas por arrendatarios, con contratos tan cortos que no les permitía mejorar el cultivo.

11) La propiedad amortizada y vinculada, situación característica de esta época que viene determinada por la imposibilidad de vender, ceder... estas propiedades, afecta al $84 \%$ de las tierras de eclesiásticos y al 81,6\% de las de seculares; es decir, la mayor parte de la tierra accitana estaba fuera del circuito comercial, lo que provocó una falta de tierras y una subida de las rentas de ésta.

12) El absentismo también estuvo muy presente en Guadix, ya que los propietarios más grandes vivían fuera de la localidad, si exceptuamos al Marqués de Cortes. Entre los propietarios forasteros destaca Nicolasa Merino, vecina de Granada, y propietaria del Cortijo de Fuente Caldera. 